\title{
EFEITO RELAXANTE DA GOMA DO CAJUEIRO EXTRAÍDA DO EXSUDATO DE Anacardium occcidentale L. SOB A CONTRAÇÃO UTERINA INDUZIDA POR OCITOCINA IN VITRO.
}

\author{
Sávia Francisca Lopes Dias ${ }^{1}$, Layane Carneiro Alves Pereira ${ }^{2}$, Marcos Meneses de Oliveira ${ }^{3}$, Rosimeire Ferreira dos \\ Santos ${ }^{4}$, Lívio César Cunha Nunes ${ }^{5}$. \\ ${ }^{1}$ Doutoranda RENORBIO/UFPI; ${ }^{2}$ Mestranda PPGFARM/UFPI; ${ }^{3}$ Discente/UFPI; ${ }^{4}$ Docente/UFPI; ${ }^{5}$ Docente/UFPI \\ *marcosmenzes@hotmail.com
}

\section{RESUMO}

INTRODUÇÃO: Dismenorreia é um termo médico usado para definir cólicas menstruais. 0 aumento da contratilidade uterina foi proposto como uma das principais causas de dismenorreia. Este estudo propôs a investigação do efeito relaxante da goma do cajueiro purificada (GCP) na contratilidade uterina de roedores in vitro. MATERIAIS E MÉTODOS: A goma do cajueiro foi extraída por incisões no tronco da árvore Anacardium occidentale $L$. e purificada em laboratório. Para investigar o efeito relaxante no útero isolado de ratos (Rattus norvegicus) os ratos foram prétratados com estradiol $(0,5 \mathrm{mg} / \mathrm{kg})$ um dia antes da eutanásia (overdose de tiopental sódico $150 \mathrm{mg} / \mathrm{kg}$ + lidocaína $10 \mathrm{mg} / \mathrm{kg}$ I.P). $O$ útero foi colocado em uma placa de Petri contendo solução Locke Ringer a $32^{\circ} \mathrm{C}$ (95\% 02 e $5 \% \mathrm{CO}$ ). Dois cornos uterinos foram separados por incisão e suspensos verticalmente em cubas de vidro $(10 \mathrm{~mL})$. Os estudos foram realizados em útero pré-contraído de

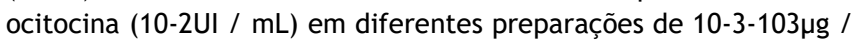
$\mathrm{mL}$ de goma. O mecanismo de ação foi estudado através da participação dos canais de potássio na presença de TEA + $5 \mathrm{mM}$. Os cortes histológicos do útero também foram analisados. Para a realização da pesquisa com animais, o estudo foi previamente aprovado pelo Comitê de Ética em Experimentação Animal da UFPI (CEEA/UFPI) sob número do processo 410/2017. RESULTADOS E DISCUSSÃO: A originalidade do material foi confirmada por espectroscopia no infravermelho. O GCP inibe a contração uterina induzida pela oxitocina in vitro de forma significativa e dependente da concentração $(E C 50=2,53 \pm 0,54 \mu \mathrm{g} / \mathrm{mL}$ ) com eficácia máxima de $97,8 \pm 0,8 \%$. Na presença de $5 \mathrm{mM}$ TEA+ o valor de Emax foi de apenas $49,05 \pm 4,33 \%$. Secções histológicas confirmaram o efeito tocolítico do GPC sob contrações tônicas induzidas. 0 estudo demonstrou a existência de um efeito terapêutico inovador do GPC, ao demonstrar sua capacidade de diminuir a contração do músculo liso uterino induzido pela ocitocina in vitro. 0 mecanismo do tocolítico sugere associado à ativação dos canais de $\mathrm{K}+$. Isso amplia as possibilidades de o CGP ser investigado para o tratamento da dismenorreia primária. CONCLUSÃO: Portanto, o estudo evidencia a atividade tocolítica associada ao GCP, através do efeito relaxante no músculo uterino após indução por ocitocina in vitro. 